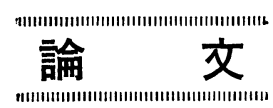

\title{
円周切欠を試験片の引張破壊現象*
}

\author{
寺沢一雄** 大谷 碧** 吉田俊夫*** 寺井 清***
}

\section{Fracture of Notched Bar Tension Specimen}

by

\section{Kazuo Terazawa, Midori ŌTAni, Toshio Yoshida and Kiyoshi TeraI} (Faculty of Engineering, Osaka University) (Welding Laboratory, Kawasaki Dockyard Co., Ltd.)

In order to investigate the characteristics of fracture stress curve of steel by notched bar tension specimen, we must clarify first the range of notch shapes which would cause an initial crack not at the contour, but at the center of notched section. Authors carried out extensive experiments and obtained some results, which are summarized as follows:

(1) Initiation of center crack of fibrous type could be observed after sectioning longitudinally the specimens which were strained and unloaded just before their fracture by means of very careful and minute adjustment of load, using a rigid and small tension testing machine of screw type (capacity, 5 tons) ( $c f$. Photos. 1 4).

(2) It was proved that "rim effect" could be recognized conspicuously on the flow stress curve of the specimen in which the center crack was initiated. By observing this rim effect, the range of notch shapes that would produce center crack was determined in detail as shown in Fig. 3.

(3) It was also proved that no contour crack was found in the case where center crack would initiate and that this phenomenon might also be observed in the reverse way. Moreover, we observed that contour crack grew slowly in comparatively a long period and was quite stable, and that, on the contrary, center crack was very unstable and accordingly the specimen broke just after its initiation. The fracture mode was shear at the contour in almost all specimens and fibrous at the center.

(4) It was presumed that micro metallurgical defects of steel might influence strongly on the initiation of ductile crack.

(Received May 19, 1961)

鋼のぜい性破壊を応力論的に究明するための方法と して, Ludwik が提唱した fracture stress curve（破 壊応力曲線）の概念に基づく手段がある．この fracture stress curve は破壞現象に関する概念的な特性 であって,これを実験的に求めるには多くの困難を伴 う.

Fracture stress curve はいわゆる brittle (cleavage) fracture stress curve $と$ ductile (fibrous) fracture stress curve に分けるのがよいと考えられてい るが，その形状は間接的に予想されているにすぎない。 とくに後者は多くの因子の影響を受ける上うで，その 特性はほとんど不明のまま残されているといっても過 言ではない。しかしぜい性破壊現象を明確にするため

\footnotetext{
* 原稿受付 昭和 36 年 5 月 19 日, 当協会第10期総会講演会(創立10 周年記念) 飞て講演(昭 36.5 )

** 大阪大学工学部

**** 川崎重工業怢式会社溶接研究室
}

には, 破壊発生点におけるこれら応力曲線の挙動を定 量的に明らかにすることがぜひ必要であろう。

鋼などの延性材料の室温付近の温度における破壞応 力曲線を求めるため Kuntze ははじめて円周切欠き試 験片を用いることを提唱し, その後多くの研究者達が これにならって実験を行なった，かれの方法によれば, 試駼片の直径 $D$, 切欠き部最小断面直径 $d$, 切欠き先 端半径 $r$ の各変数を組み合わせ多軸応力状態を design し，これがある実験条件の範囲において切欠き断面の 大部分で一定となり，かつ断面の center (designさ れた多軸応力部)で crack（破壊）が発生することを子 期して解析する。しかしたとえ多軸状態が一定となる 条件においても，もしも crackが center において発 生せず，切欠き底部 (contour)において始まっておれ ば, design した triaxiality は上述の $r$ $d$, とくに $r に よ り$ 变わるから, その発生直後から crack 先端局 
部の応力状態はさらに高度の多軸性をおびて変わった ものとなり，もしこれを無視して最初に design した 多軸応力状態であるとして解析すれば誤った結論を与 えるであろう。

切欠き試験片を用いる場合に, center crack の発 生条件を明らかにすることが重要なのはこのためであ る。

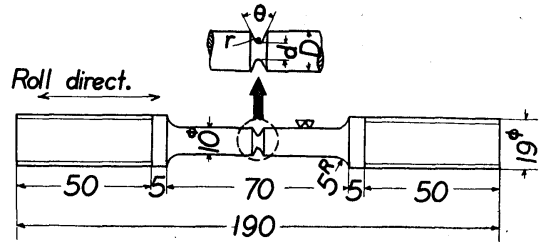

Fig. 1 Notched bar tension specimen

Table 1 Steel tested

\begin{tabular}{|c|c|c|c|c|c|c|c|c|c|c|}
\hline \multirow{2}{*}{ Steel } & \multirow{2}{*}{$\begin{array}{l}\text { Thick. } \\
\text { (mm) }\end{array}$} & \multicolumn{5}{|c|}{ Chemical analysis (\%) } & \multicolumn{4}{|c|}{ Mechanical properties (JIS No. 4 specimen) } \\
\hline & & $\mathrm{C}$ & $\mathrm{Si}$ & $\mathrm{Mn}$ & $\mathrm{P}$ & $\mathrm{S}$ & $\begin{array}{c}\text { Y.P. }{ }^{*} \\
\left(\mathrm{~kg} / \mathrm{mm}^{2}\right)\end{array}$ & $\begin{array}{c}\text { T.S. } \\
\left(\mathrm{kg} / \mathrm{mm}^{2}\right)\end{array}$ & $\begin{array}{c}\text { Elong. } \\
(\%)\end{array}$ & $\begin{array}{l}\text { Red. of } \\
\text { area }(\%)\end{array}$ \\
\hline Killed steel & 25 & 0.14 & 0.20 & 0.60 & 0.018 & 0.024 & $24 \cdot 5$ & $44 \cdot 9$ & $40 \cdot 0$ & $67 \cdot 1$ \\
\hline Round bar & $\begin{array}{c}19 \\
\text { (dia.) }\end{array}$ & 0.14 & 0.01 & $0 \cdot 49$ & 0.017 & 0.036 & $27 \cdot 5$ & $44^{\circ} 0$ & $42 \cdot 7$ & $65^{\circ} 0$ \\
\hline
\end{tabular}

* Y.P. : lower value

Table 2 Results of notched bar tensile test to confirm directly the crack initiation

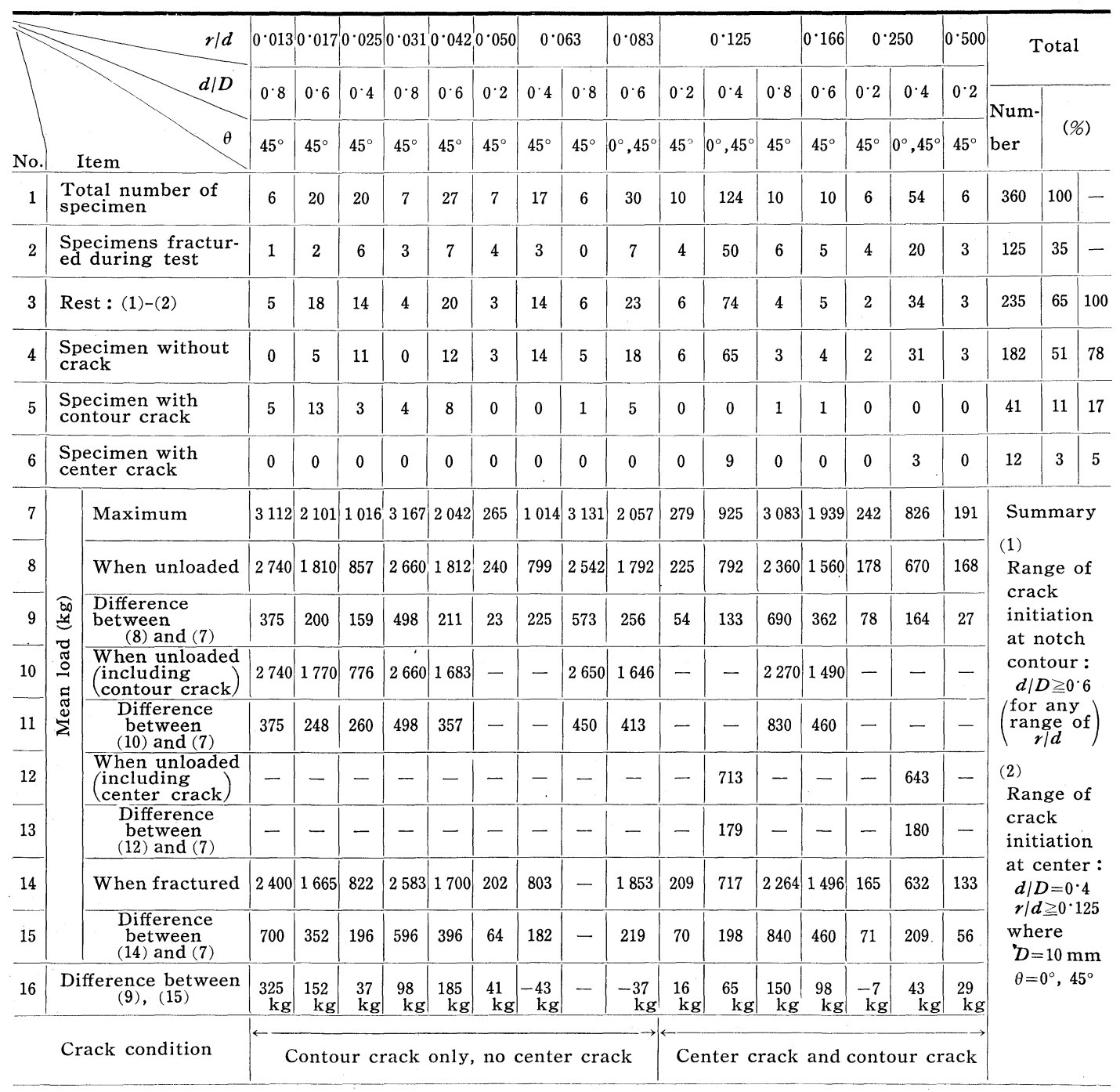


G. Sachs, J.D. Lubahn, M.L. Fried, D. McAdam あるいは小倉信和らの各氏は以上の点を明確 にすべく, crack が center で生ずると考えられる試 騟片を用いて発生㨁後の center crack を值接に確認 して, その発生する条件を求めるためにあらゆる角度

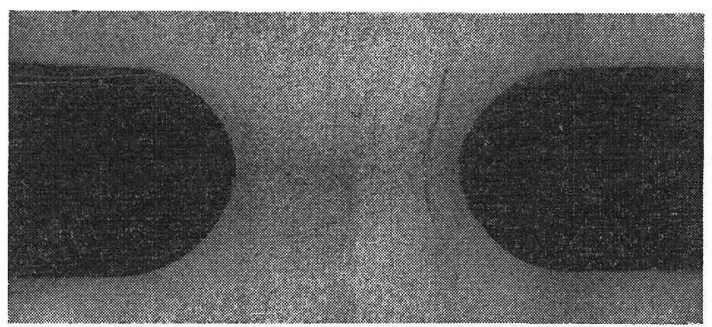

$d=4 \mathrm{~mm}, r=1 \mathrm{~mm}, \theta=0^{\circ}$, unloaded at $615 \mathrm{~kg}$

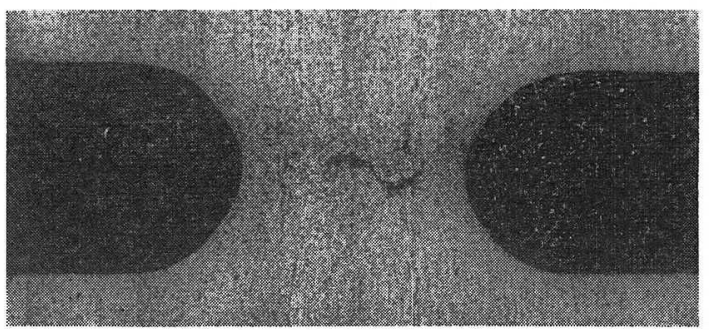

$d=4 \mathrm{~mm}, r=1 \mathrm{~mm}, \theta=0^{\circ}$, unloaded at $640 \mathrm{~kg}$

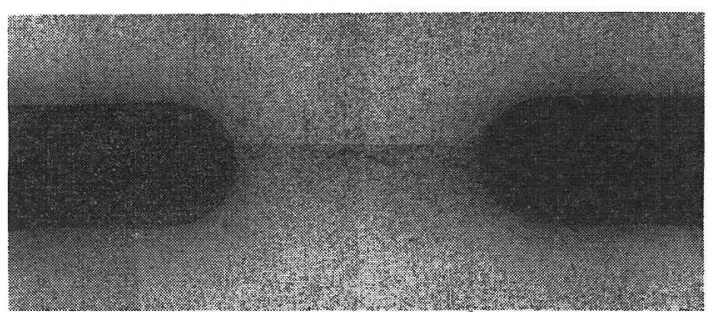

$d=4 \mathrm{~mm}, r=0.5 \mathrm{~mm}, \theta=0^{\circ}$, unloaded at $795 \mathrm{~kg}$

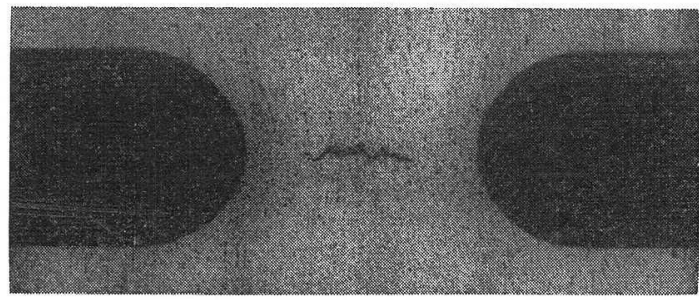

$d=4 \mathrm{~mm}, r=1 \mathrm{~mm}, \theta=0^{\circ}$, unloaded at $555 \mathrm{~kg}$

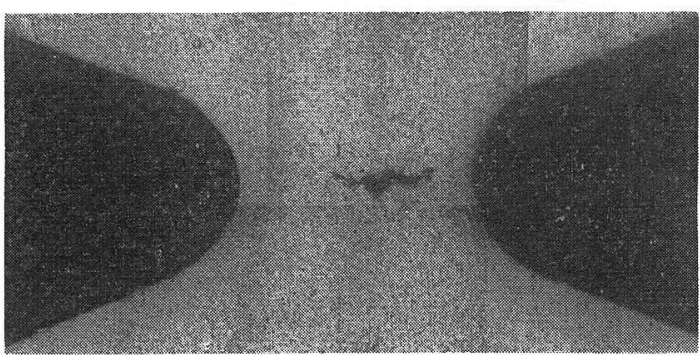

$d=4 \mathrm{~mm}, r=1 \mathrm{~mm}, \theta=45^{\circ}$, unloaded at $700 \mathrm{~kg}$

Photo. 1 Examples of center crack
から実験を行なったのであるがこれらはすべて失敗 している。著者らはその原因が，（1）切欠形状の不 適当と，（2）破断直前における試験機の微細な荷重 調節の不充分にあると考えた。

実験には Table 1 に示すようなびよう(鋲)材とキ ルド軟鋼板を用いた.

試駘片の $D$ は $10 \mathrm{~mm}$ とし $, r, d, \theta$ を Table 2 に 示すように広範囲に変化させて, Fig. 1 に示すように

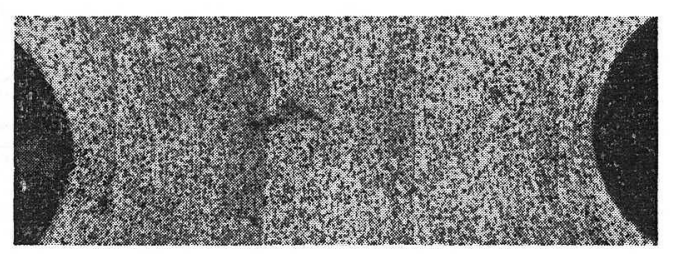

$d=4 \mathrm{~mm}, r=0.5 \mathrm{~mm}, \theta=45^{\circ}$, unloaded at $735 \mathrm{~kg}$

Photo. 2 Example of center crack just initiated

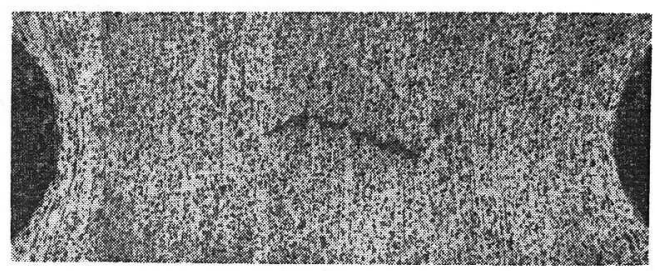

$d=4 \mathrm{~mm}, r=0.5 \mathrm{~mm}, \theta=0^{\circ}$, unloaded at $795 \mathrm{~kg}$

Photo. 3 Example of center crack fairly developed

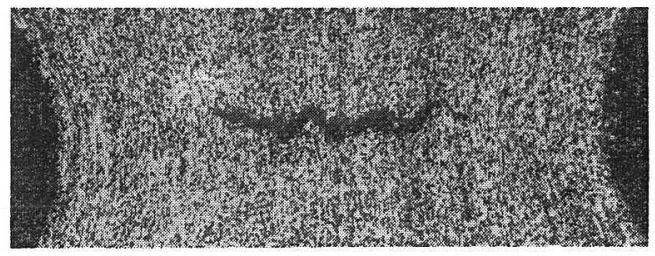

$d=4 \mathrm{~mm}, r=1 \mathrm{~mm}, \theta=0^{\circ}$, unloaded at $555 \mathrm{~kg}$

Photo. 4 Example of center crack before fracture

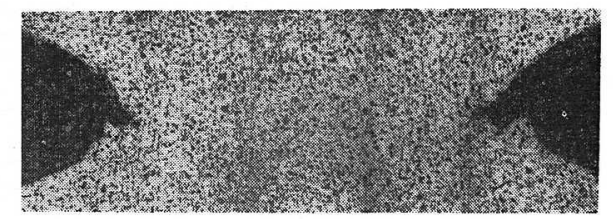

$d=4 \mathrm{~mm}, r=0.1 \mathrm{~mm}, \theta=45^{\circ}$, unloaded at $850 \mathrm{~kg}$

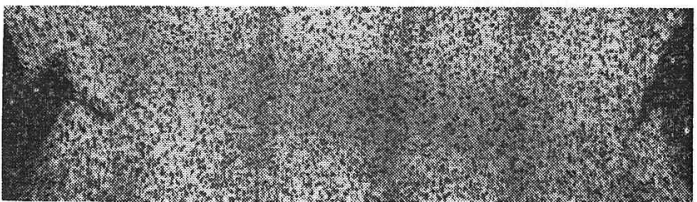

$d=6 \mathrm{~mm}, r=0.5 \mathrm{~mm}, \theta=45^{\circ}$, unloaded at $1600 \mathrm{~kg}$

Photo. 5 Examples of contour crack

$$
\begin{aligned}
& \text { Upper photo..........sharp notch } \\
& \text { Lower photo..........shallow notch }
\end{aligned}
$$


試験片を 360 本作製した。 また引張試験機には油圧型 のものや電動モータ一駆動の大形スクリュ一型のもの の使用を避けて, 小形試験片の荷重の微小調節に適し た手回し式のスクリュー型試験機（容量5 t ) を用いた。 試験片を破断值前まで引張ってから unloadして,
試験片中心切断面を研摩して検鏡した，その結果 12 本の試験片において, 切欠部に center crack が見出 されたなお破壞はすべて fibrous 型であった.

試験結果を一括して Table 2 にまとめて示す。 た, contour crack と center crack の発生範囲は : Contour crack

(A)
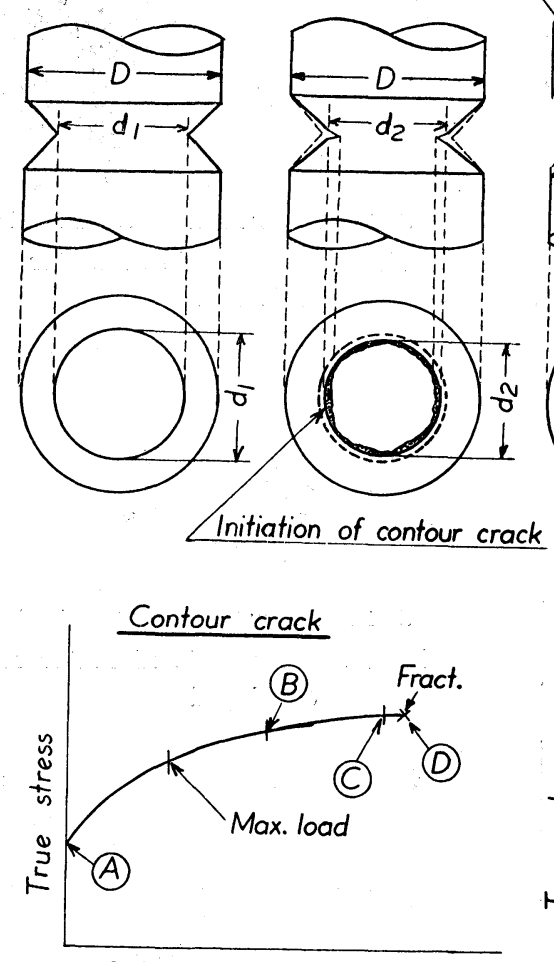

Reduction of area

(A)

(B)
Additional

(B) stretching

(C)

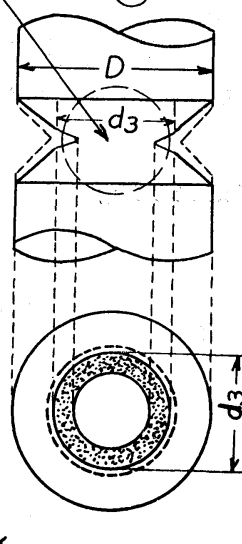

$$
d_{1}>d_{2}=d_{3}=d_{4}
$$

(D)
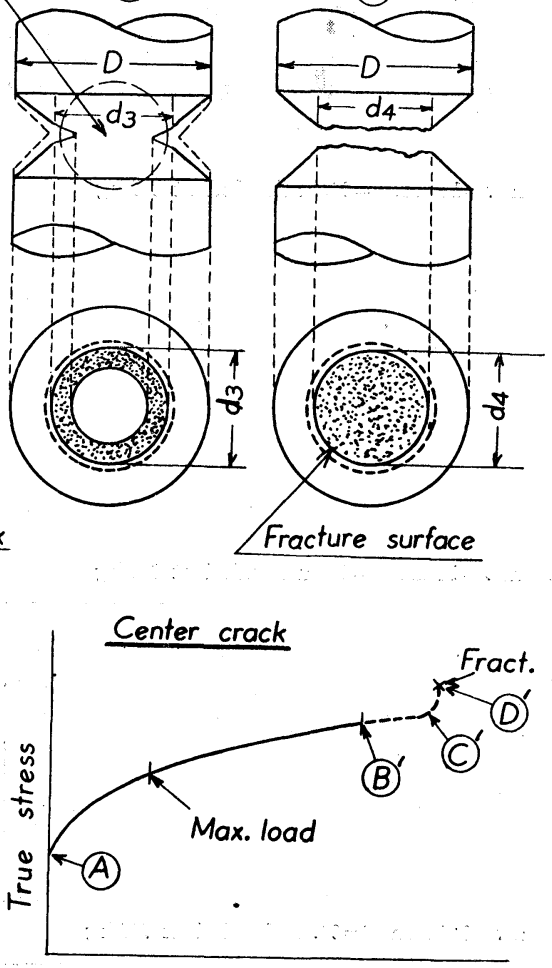

Reduction of area

(C)

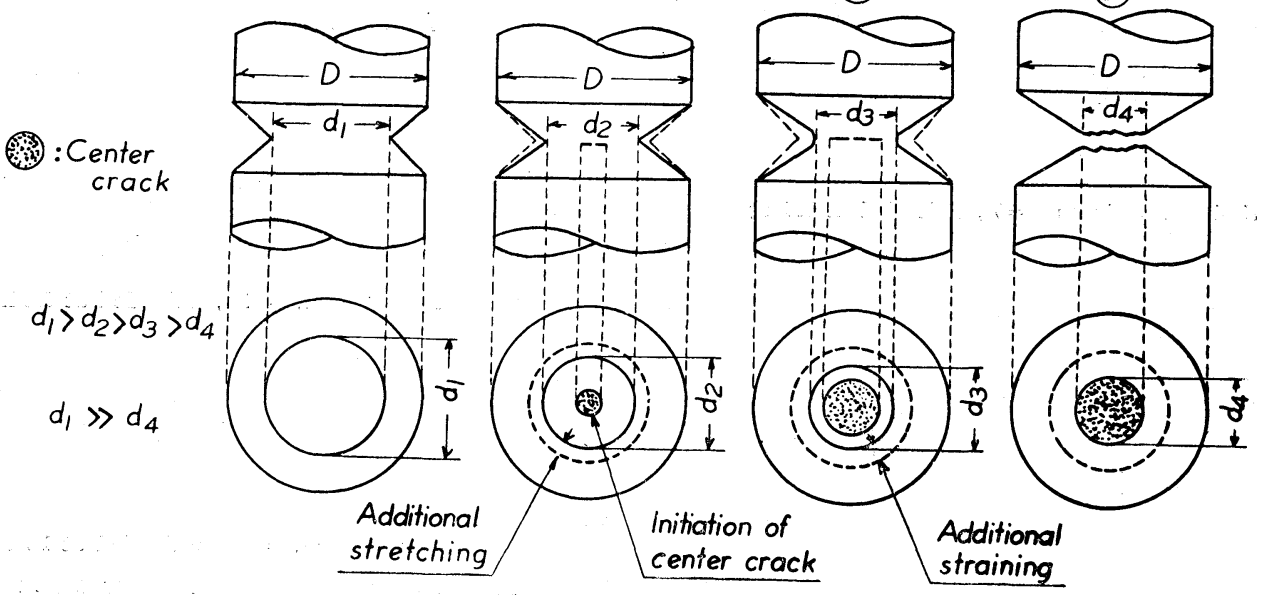

(D)

Fig. 2 Schematic explanation of the shapes of stress-strain curves affected by mode of crack initiation 
Table 2 の中の summary 欄に記すとおりである.す なわち center crack 発生の有無は, 主として $d / D$, $r / d$ のいんにより定められている.

$d / D$ が 0.4 を越えるといかなる $r / d$ に対しても center crack は発生せず. また $r / d$ が 0.083 以下で はいかなる $d / D$ に対しても center crack は発生しな い.この結果に基づいて将来行なわれてきた実験を検 討すると，kuntze の場合は前者 $(d / D)$ のみを採り上 げて論じており，rの影響に関しては触れておらず， また一方 McAdam, Sachs をはじめとする米国の研 究者らは後者 $(r / d)$ のみを採り上げて解析を進め, $d / D$ に関しては触れていない不合理のあることがわ かる。また $\theta$ については小倉氏はあまり影響がない としているが，本報告の結果もこれを肯定しているよ うである. Photo. 1〜 5 は以上求めた crack の代表的 な顕微鏡写真を示す。

なお前述したように小形のスクリュ一型引張試験機

\begin{tabular}{l|c|c}
\hline Method & $\begin{array}{l}\text { After sectioning } \\
\text { specimen }\end{array}$ & By rim effect \\
\hline Center crack & 0 & $\triangle$ \\
Contour crack & - & $\Delta$ \\
\hline
\end{tabular}

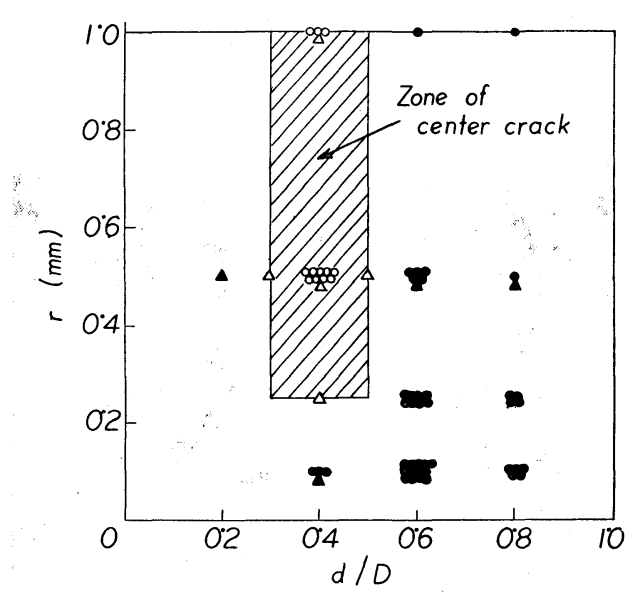

Fig. 3 Summary of test showing the ranges of center and contour crack initiation
により荷重の微小な調節をすることが重要である.

いま center crack の発生した切欠形状 ( 2 系列,

30 本) の試験片について見ると破壞時の平均荷重は $613 \mathrm{~kg}$ であるのに対し, center crack を見出したも のにおける unload 時の平均荷重は $611 \mathrm{~kg}$ できわめ て接近しているにすぎない。したがって，もし荷重の 調節が適切に行なわれないと，切欠き条件は充分でも crack の発生が全然見られなかったり，あるいは試験 片は破断してしまうであろう。

なお著者らは center crack の発生範国をより詳細 に求めるため McAdam の提唱する rim effect によ る方法 (Fig. 2 参照) を用いて各切欠き形状の試験片 の flow curve を測定した.この結果は Fig. 3 に示 すように前述の直接証明法の結果と大体一致していた.

なお，本研究は文部省科学試験研究費補助金の交付 を受けて行なわれたものである

また研究の計画と実験に際し，有益な御助言を賜わ った東京大学木原博教授ならびに造船協会電気溶接研 究委員会(第 6 分科)の各位に深、感謝するものである. 末筆ながら運輸技術研究所小倉信和氏は貴重な研究 データーと調査資料を惜しみなく著者らに教示された。

同氏の御好意がなかっったならば，本研究の実施はさ らに著しく困難の度を加えたであろうことをとくに記 して，嬮く感謝の意を表する次第である。

\section{参考 文 献}

1) P. Ludwik and R. Scheu, Stahl u. Eisen, 43, p. 999 (1923)

2) E. Orowan, Reports on Progress in Physics, XII (1949) Physical Society

3) G. Sachs, et al., Final Rep. to NACA, on the Tension Properties of Al Alloys in the Presence of Stress Raisers (Part 1) (1947) (cf. Ref. (6), p. 103)

4) G. Sachs and J. Lubahn, Weld. J., p. 53-s (1946)

5) M. Fried and G. Sachs, Special Tech. Publn., 87, ASTM, p. 83 (1948)

6) D. McAdam and R. Mebs, Tech. Publn., 1615, AIMME (1943)

7）小倉信和，日本造船研究協会報告， 9, p. 25 (1955) 関する未 発表資料

8) J. Lubahn, Fracturing of Metals, ASM, p. 90 (1948) 